\title{
An Examination Of Global Market Segmentation Bases And Strategic Positioning Decisions
}

Salah S. Hassan, (E-mail: hassan@gwu.edu), George Washington University Stephen H. Craft, (E-mail: scraft@stephencraft.com), Birmingham-Southern College

\begin{abstract}
This paper examines the conceptual linkages between global segmentation strategy and brand positioning from the perspective of firms operating in increasingly globalized markets. The manuscript suggests the combined use of macro/country-level as well as micro/behavioral-level bases of segmentation in order to leverage similar strategic positioning across global markets. The analysis presented paves the way for embarking on future research to enrich the academic understanding and managerial practice of linking global segmentation with strategic positioning decisions.
\end{abstract}

\section{Introduction}

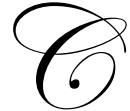

an the decisions surrounding global market segmentation be based solely upon geopolitical and economic factors or can global segmentation decisions be based upon lifestyle and behavioral variables? In an increasingly technological and globalizing marketplace where customer segments are becoming more similar across national boundaries, behavioral and lifestyle segmentation is becoming a necessary addition to geopolitical and economic segmentation for effective international marketing (Aulakh and Kotabe 1993, Helsen, Jedidi and DeSarbo 1993, Nachum 1994, Luqmani, Yavus, and Quraeshi 1994). Segmentation strategy development is complicated in global markets by the need for companies to make related strategic positioning decisions in an increasingly competitive and transparent marketplace in order to leverage brand equity and achieve economies of scale. In short, segmentation strategy development does not simply involve the selection of desirable market segments, but also includes the corresponding need to effectively position brands relative to the identified market segment. Toward that end, the purpose of this paper is to begin the process of exploring the relationship between brand positioning strategies and bases of segmentation in international markets.

The decision to segment world markets is closely related to the degree of globalization achieved in a given market. One should hardly expect a single universal marketing strategy to be effective on a global basis given that there are no more mass markets in the United States. In contrast, if one or more bases exist for market segmentation that cut across national boundaries, then marketing strategies might be developed that will work for similar customer segments around the globe. The existence of these intra-market segments might create important opportunities and challenges for firms seeking to establish brand positions in multiple markets - an increasingly common strategic goal.

\section{Bases for Global Market Segmentation}

The majority of early segmentation efforts were based on macro considerations that include factors such as economic (Kotler 1986), cultural (Whitlock 1987), geographic (Daniels 1987), and technological (Huszagh 1986). These pre-determined country bases are inadequate for segmentation, according to current research, when considered without behavioral bases (Helsen, Jedidi, and DeSarbo 1993, Nachum 1994, Hassan, Craft and Kortam 2003). For example, pre-determined country clusters will be inadequate without a full account for the degree of homogeneity related to buyers' responsiveness to the global marketing program. 
Global marketing has evolved to imply global segments being defined based upon market variables other than national boundaries. A synthesized or hybrid approach that considers both country bases as well as buyer response bases is more realistic. This synthesis-based inter-market segmentation approach refers to ways of describing and reaching market segments that "transcend" national boundaries or geographically defined markets (Kale and Sudharshan 1987). The emphasis in inter-market segmentation is on combining multiple segment bases including, but not limited to, national boundaries. There are sizable world markets where consumer segments are converging across cultural and national boundaries. The key to successfully leveraging brand equity is to identify these segments on an inter-market basis and to develop strategies to reach them with globalized brands. The existence of inter-market segments can be an important condition for the success of cross-country marketing programs. Synthesis or hybrid segmentation strategies were developed as frameworks to evaluate markets on a worldwide basis and to identify the attributes of brands that are suitable for the implementation of global marketing programs (Helsen, Jedidi and DeSarbo 1993, Luqmani, Yavus, and Quraeshi 1994, Kale and Sudharshan 1987, Kreutzer 1988, Hassan and Katsanis 1991.)

Market segmentation strategy should be examined to determine the best bases for global brand positioning. Segments should be designed so that buyers are seeking similar benefits and therefore exhibiting similar behavior in buying a product. Market segments in a global context are best understood as groups of buyers who share the need and desire for a product and the ability to pay for it, not just those who share a national border. Although these buyers may live in different areas of the world and come from very different backgrounds and value systems, they have commonalties in association with a given global brand. These similarities are often associated with the brand's image and the lifestyle it projects (Luqmani, Yavus and Quraeshi 1994).

The development of inter-market segments means that global firms can benefit from integrating macrolevel bases with micro-level bases in their segmentation. The attraction to similar brand benefits, similar patterns of purchase and consumption behavior, and specific shared values should be the emphasis of the firm's strategy in responding to global segments that transcend the geopolitical boundaries of nations. Global marketers often target lifestyle similarities. For example, targeting do-it-your-self consumers allows Black \& Decker to enjoy great popularity in London, Los Angeles and Johannesburg. Those who like to work around their home may live in diverse regions characterized by very different value systems as well as very different building materials, but similarities should dominate when comparing segment members.

Traditionally, segmentation researchers have segmented the market based on objective predetermined attributes (Wind 1978, Wind 1986). This self-styled a-priori segmentation method selects a pre-recognized battery of descriptive characteristics for each country. Recent segmentation research calls for a micro-based measurement technique that focuses on buyer preferences. This post hoc method utilizes a battery of variables that seek to differentiate buyer preferences (Green and Krieger 1991). The synthesis or hybrid method being discussed segments the world markets based on similar purchase patterns exhibited in multiple countries thereby allowing countries to potentially belong to multiple segment clusters. Effective segmentation methods ultimately will need to integrate country-based factors with buyer-based variables.

An integrated approach would represent a more reasoned and realistic response to the forces of market globalization such as consumer needs converge (Levitt 1983). Therefore, it is proposed that effective global segmentation will be based upon a synthesis or hybrid use of segmentation bases that includes relevant macro-level factors (i.e., geopolitical and economic) as well as appropriate micro-level variables (i.e., lifestyle and behavioral). Major facets of this approach include: integrating country variables with behavior patterns; not assuming total homogeneity of the country segment; acknowledging the existence of a degree of similarity across national boundaries; considering the bases of segmentation to be dynamic in nature; and, defining market globalization as a matter of degree.

The synthesis or hybrid approach assumes that treating each country as a totally homogeneous market is not realistic (Jain 1989). Also, it will be unrealistic to assume the existence of a single world segment that homogeneously responds to standardized marketing programs. The basic ideas of the synthesis or hybrid approach are: assumption of variable degrees of heterogeneity and homogeneity in buyers' preferences for global brands; any 
degree of preference heterogeneity or homogeneity for global brands can be attributed to both macro-bases (i.e., country factors), micro-bases (i.e., behavioral variables), and many possible combinations; any degree of preference heterogeneity can be addressed by introducing adaptive variations in the marketing program.

\section{Strategic Positioning}

Marketing based on an expanded view of world markets requires a careful examination of complex decisions related to strategic positioning in conjunction with segmentation. Should a firm position its brand the same way in all markets? Should global marketing strategy have uniform brand image as a goal? What combination of global positioning strategies can be employed?

\section{Segmentation-Based Strategic Positioning}

A review of the extant research on international segmentation reveals that a number of segmentation researchers have stressed the importance of the relationship between segmentation and positioning decisions (Douglas and Craig 1995, Ries and Trout 1986, Hassan, Craft and Kortam 2003). Segmentation and positioning decisions are central to the development of global marketing strategy. Positioning is used to refer to the firm's decision to critically manage the place that its brand and corporate image occupy in a given market including the type of product benefits to be stressed and the type of segments to be targeted (Douglas and Craig 1995, Ries and Trout 1986, Reis 1996). In the context of international marketing, there is consensus in the literature on the need to base positioning decisions on a broader perspective that includes an understanding of differences and similarities from one market to another. Therefore, positioning is understood to be a strategy to identify and direct marketing resources among intended market segments. Under this strategy that we term "segmentation-based strategic positioning," the firm would encourage the development of homogeneous buyer responses for demand that differs from responses received from other market segments.

A decision to position brands differently in differing countries based upon local preferences or opportunities may create challenges. As the brand matures in the market, the organization may find itself with the desire and opportunity to optimize the success achieved in one market to reach an even great audience of global consumers. Nestlé build a successful brand in the U.S. by focusing on loyalty as a segmentation bases. Nestlé's instant coffee leveraged the corporation's success in non-coffee consuming cultures to appeal to attitude and usage patterns of other cultures.

\section{Discussion}

Firms competing in global markets must identify appropriate segments, whether they are country groups or individual buyer groups, of potential customers with homogeneous attributes who are likely to exhibit similar buying behavior patterns. Four approaches to global segmentation include: (a) identifying clusters of countries that demand similar products (that is, regional selling giving more weight to geopolitical and economic segmentation factors); (b) targeting different segments in different countries with the same product (that is, differentiated selling emphasizing behavioral and lifestyle segmentation factors) (Takeuchi and Porter 1986); (c) identifying segments present in many or most countries (that is, universal selling striking a hybrid balance between various macro and micro segmentation factors); and (d) focusing on similar segments that demand similar products (that is, niche selling with a focus on cross-national similarities in need for unique product attributes and usage patterns).

Universal segmentation and global niche marketing are argued to be the most innovative two of the four approaches to segmentation and also the most likely approaches to give the firm a significant competitive advantage. Principally, the competitive advantage comes because brand image can be leveraged across markets (that is, globally transcending distinctive competency). The practice will afford the brand a reputation and coherence in image and positioning which is reinforced across countries and cultures. The alternative segmentation approaches have the advantages of considering differences among countries and of accommodating these differences through adaptation or by concentrating marketing efforts to succeed in a specific segment (Lambin 1997). However, the later alternative segmentation strategies could suffer the disadvantage of high cost of differentiation, limited economies of 
scale, as well as vulnerability to local market changes. Therefore, the synthesis or hybrid approach that integrates country level and behavioral characteristics is viewed as the preferred segmentation strategy.

The synthesis or hybrid segmentation strategy looks for similarities among countries across world markets. Traditional segmentation with its emphasis on differentiation is multi-domestic (i.e., they tend to minimize similarities and highlight differences). The synthesis or hybrid segmentation strategy actively seeks homogeneity in brand, image, marketing tools and advertising message, while the multi-domestic approaches to global market segmentation maintains emphasis on differences from market to market. However, the ultimate agenda is not to have a uniform brand positioning worldwide but to develop brand positioning that is as standardized as possible while allowing for local conditions as necessary and desirable (Keegan and Schlegelmich 1999).

\section{Future Research}

Global market segmentation and strategic brand positioning decisions need to be linked and substantiated through rigorous and relevant research. Toward that end, four research agenda items can be recommended to push forward the boundaries of our understanding in the area of global market segmentation. The resulting research should also address critical needs for marketing researchers and strategists aiming to develop and implement effective global strategies.

The first research agenda priority is to determine when global marketers should pursue synthesis or hybrid segmentation strategies. This research stream would addresses the rationale underlying hybrid global market segmentation and should result in analytical tools for the evaluation of each market's needs and their corresponding brand positioning. The research ought to be conducted mindful of making practical economic and managerial sense in relation to the dimensions of accessibility (i.e., market segmentation transaction costs) and substantiality (i.e., segmentation-related economies of scale).

The second research agenda priority is to substantiate how global marketers can achieve a logical design of synthesis/hybrid market segmentation that will facilitate establishing a coherent positioning strategy. This research stream would encompass the practical consideration of implementation of a synthesis or hybrid global market segmentation. The research effort should seek to precisely define how the characteristics of segmentation bases, targeting agendas, and targeting techniques can be made operational and used to augment positioning decisions made and thereby translated into a relevant and effective marketing mix design.

The third research agenda priority is to examine the performance implication issues relevant to the adoption of synthesis or hybrid global market segmentation. This research question should be addressed by examining the success or failure of adopting synthesis or hybrid global market segmentation strategies. This research should raise a number of issues related to the effectiveness of global marketing research and marketing information systems that help support the implementation of segmentation and positioning strategies.

The fourth research agenda priority is to examine how synthesis or hybrid global market segmentation and positioning strategy can be monitored, benchmarked and evaluated. This fourth research stream should address the obvious need to measure the differing contributions of synthesis/hybrid global market segmentation strategies to positioning effectiveness and the firm's other strategic marketing ends.

\section{References}

1. Aulakh, Preet S. and Masaaki Kotabe, "An Assessment of Theoretical and Methodological Development in International Marketing: 1980-1990.” Journal of International Marketing, Vol. 1, No. 2, pp.5-28, 1993.

2. Daniels, John D., "Bridging National and Global Marketing Strategies through Regional Operations," International Marketing Review, Vol. 2, No. 3, pp. 29-44, 1987.

3. Douglas, Susan P. and C. Samuel Craig, Global Marketing Strategy. McGraw-Hill, 1995.

4. Green, Paul E. and Abba M. Krieger, "Segmentation Markets with Conjoint Analysis," Journal of Marketing, Vol. 55, No. 4, pp. 20-31, 1991. 
5. Hassan, Salah S., Stephen H. Craft, and Wael Kortam, "Understand the New Bases for Global Market Segmentation," Journal of Consumer Marketing, Vol. 20, No. 5, pp. 446-460, 2003.

6. Hassan, Salah S. and Lea P. Katsanis, "Identification of Global Consumer Segments: A Behavioral Framework," Journal of International Consumer Marketing, Vol. 3, No. 2, pp. 11-28, 1991.

7. Helsen, Kristiaan, Kamel Jedidi and Wayne S. DeSarbo, "A New Approach to Country Segmentation Utilizing Multinational Diffusion Patterns,” Journal of Marketing, Vol. 57, pp. 60-71, 1993.

8. Huszagh, Sandra M., Richard J. Fox, and Ellen Day, "Global Marketing: An Empirical Investigation," Columbia Journal of World Business, Vol. 20, No. 4, pp. 31-43, 1986.

9. Jain, Subhash C., "Standardization of International Marketing Strategy: Some Research Hypothesis," Journal of Marketing, January, pp. 70-79, 1989.

10. Kale, Sudhir H. and Davanathan Sudharshan, "A strategic Approach to International Segmentation." International Marketing Review, Vol. 4, pp. 60-70, 1987.

11. Keegan, Warren J., and Bobo B. Schlegelmich, Global Marketing Management: A European Perspective. London: Prentice Hall, 1999.

12. Kotler, Phillip, "Global Standardization-Courting Danger,” Journal of Consumer Marketing, Vol. 3, No. 2, pp. 13-15, 1986.

13. Kreutzer, R. T., "Marketing Mix Standardization: An Integrated Approach in Global Marketing," European Journal of Marketing, Vol. 22, No. 10, pp. 19-30, 1988.

14. Lambin, Jean-Jacques., Strategic Marketing Management. London: McGraw-Hill, 1997.

15. Levitt, Theodore., "The Globalization of Markets," Harvard Business Review, Vol. 61, pp. 92-102, 1983.

16. Luqmani, Mushtaq, Ugur Yavas and Z. A. Quraeshi, "A Convenience-oriented Approach to Country Segmentation," Journal of Consumer Marketing, Vol. 11, No. 4, pp. 29-40, 1994.

17. Nachum, L., "The Choice of Variables for Segmentation of the International Market." International Marketing Review, Vol. 11, No. 3, pp. 54-67, 1994.

18. Ries, Al, and Jack Trout, Positioning: The Battle for Your Mind. New York: McGraw-Hill, 1986.

19. Ries, Al., Focus: The Future of Your Company Depends on It. Harper Collins: 1996.

20. Takeuchi, H. and Michael E. Porter, Three Roles of International Marketing in Global Industries, " in: Porter, Michael E., (ed.), Competition in Global Industries. Boston: The Harvard Business School Press, 1986.

21. Whitlock, J. M., "Global Marketing and the Case of for International Product Standardization," European Journal of Marketing (U.K.), Vol. 21, No. 9, pp. 32-44, 1987.

22. Wind, Yoram., "Issues and Advances in Segmentation Research." Journal of Marketing Research, Vol. XV, pp. 318-37, 1978.

23. Wind, Yoram., "The Myth of Globalization.” Journal of Consumer Marketing, Vol. 3, pp. 23-6, 1986. 
Notes 